\title{
URBAN SLUMS AND CHILDREN'S HEALTH IN LESS-DEVELOPED COUNTRIES
}

\author{
Andrew K Jorgenson \\ Department of Sociology \\ University of Utah \\ andrew.jorgenson@soc.utah.edu

\section{James Rice} \\ Department of Sociology \\ New Mexico State University \\ jcrice@nmsu.edu
}

\begin{abstract}
We utilize first-difference panel regression analysis to assess the direct effect of urban slum prevalence on national level measures of under-5 mortality rates over the period 1990 to 2005. Utilizing data on 80 less developed countries, the results illustrate increasing urban slum prevalence over the period is a robust predictor of increasing child mortality rates. This effect obtains net the statistically significant influence of gross domestic product per capita, fertility rate, and educational enrollment. Cross-sectional analyses for 2005 that include additional controls provide further evidence of the mortality / urban slum relationship. The results confirm urban slum prevalence growth is an important contextual dynamic whereby the social production of child mortality is enacted in the less developed countries.
\end{abstract}

\section{INTRODUCTION}

Slums have long been a dimension of the urban landscape, and the basic features of slum life have changed little over time. What has changed in recent decades is the increasing depth and magnitude of urban slum conditions in less developed countries (United Nations Population Fund [UNFPA] 2007). The "concentrated disadvantage" (Vlahov et al. 2007) characteristic of many urban slums, moreover, constitutes an increasingly prominent structural characteristic shaping population-level patterns of health and illness.

Worldwide the aggregate urban slum population grew 39 percent over the period 19902005 (United Nations Human Settlements Programme [UN-HABITAT] 2008). Currently the one billion individuals living in urban slum conditions comprise roughly one-third of the world's total urban population, 43 percent of the urban population in the developing countries, and 78 percent of the urban population in the poorest, least developed countries (UN-HABITAT 2003a, 2006). Recent projections suggest the overall urban slum population worldwide will increase 
steadily in the coming decades by an estimated 27 million new slum residents annually from 2000-2020 (UN-HABITAT 2003a).

The remarkable growth of urban slums in recent decades is a reflection of the urbanization of poverty; such reorganization gives form to evolving "risk spaces" (Fitzpatrick and LaGory 2000) or areas in which a sub-population is disproportionately subject to a myriad of hazards relative to other segments of society. In stark contrast to the generally beneficial health consequences of urban social organization, urban slum conditions are characterized by an observable "urban penalty." Indeed, urban slum areas often exhibit poorer health outcomes, lower life expectancy rates, lower levels of education, and diminished economic opportunities relative to non-slum urban populations (UN-HABITAT 2006).

While the living conditions within the urban slums in less developed countries seem particularly harmful for the health and well being of young children, little if any prior comparative international research exists on such associations. We contend this scarcity was due primarily to lack of data on urban slum size and prevalence in macro-comparative contexts. Fortunately, comparable national-level panel data on the percent of total populations living in urban slum conditions are now available for a moderate number of less developed countries, allowing for empirical assessments of the effects of urban slum conditions and their growth on the health of the youngest and most vulnerable segments of domestic populations. Thus, we analyze the extent to which child mortality rates in less developed countries are affected by the percent of total populations living in urban slum conditions, net of a variety of other factors.

\section{THE BUILT URBAN ENVIRONMENT AND THE SOCIAL PRODUCTION OF UNDER- FIVE MORTALITY}

Social epidemiology focuses on the social-organizational production of disproportionate illness among disadvantaged segments of a population (Berkman and Kawachi 2000; Krieger 2001; Link and Phelan 1996). ${ }^{1}$ This approach frequently adopts an individual-level unit of analysis but is increasingly embracing a population-level perspective (Macintyre and Ellaway 2000); this entails an effort to examine the socio-organizational patterns and large-scale structural arrangements that influence the health outcomes of a defined population. In turn, this often necessitates the consideration of poverty, discrimination, and various forms of inequality within society as factors influencing differential morbidity and mortality rates (Link and Phelan 1996; Krieger 1999).

The recognition that social factors shape health and illness has a long history (Engels [1845] 1968; Yankauer 1950), and yet social epidemiology is a relatively new and often contested branch of epidemiology as it challenges the overly narrow and "desocialized" biomedical model that focuses upon individual-level biological and behavioral risk factors (Farmer 1999; Berkman and Kawachi 2000; Farmer et al. 2006). The biomedical model investigates why a particular individual is sick, whereas social epidemiology involves inquiry into the societal dynamics shaping susceptibility to rather than the biomedical mechanisms of disease causation (Krieger 2001).

The objective of social epidemiology is to document the manner in which "societies shape patterns of disease" (Waitzkin 1981; Link and Phelan 1996). Such insights are more provocatively conceptualized as "structural violence" (Galtung 1969; Farmer 1999; Farmer et al.

\footnotetext{
${ }^{1}$ We use the term "social epidemiology" in a broad, general sense which also recognizes the insights and contributions of medical sociologists.
} 


\section{JOURNAL OF WORLD-SYSTEMS RESEARCH}

2006). Recognizing that overt and episodic violence is but one aspect of the injury suffered by the poor and marginalized, structural violence refers to the inequitable social structural and institutional patterns that predominantly disadvantage particular groups in society. Galtung (1969) argues embedded, systematic patterns that inhibit the fulfillment of basic needs of some members of society are less easily recognizable than direct violence and yet are more stable and durable; Farmer (1999) further notes that structural violence is expressed as individual level pathology and population level disparities in morbidity and mortality. Arguably, structural violence underlies the remarkable expansion of urban slums in developing countries in recent decades and the inadequate built urban environment is increasingly the site of the social production of disparities in health and illness.

The built environment consists of the "tangible settings which people create for repeated use" (Dunlap, Michelson, and Stalker 2001:1) and "that part of the environment constructed by human intention and effort" (Kilmartin 2001:167). The inadequate built urban environment arguably has a direct, though not deterministic, influence on health disparities that is not synonymous with or reducible to invocations of "urbanization" or "poverty." It is an expression of prevailing social and economic organization and, in turn, the social production of uneven health and illness. Socio-economic processes contribute to the formation of urban slum conditions but it is the dilapidated, semi-permanent built urban environment in which inequities in health and illness are increasingly enacted. Poverty, overcrowding, malnutrition, insufficient garbage disposal, lack of adequate water drainage, and unsafe drinking water and sanitation coalesce around the social organization of marginalized populations in urban slums. The inadequate built urban environment within many developing countries, therefore, constitutes a key barrier to progressive social well being and even a catalyst of retrogression; this may be particularly the case for children (Satterthwaite 1993; Bartlett 2003). The five illnesses at the root of a majority of child deaths in the developing countries include pneumonia, diarrhea, malaria, measles, and HIV/AIDS (UN-HABITAT 2007b). Each is prevalent in many urban slums due to substandard living conditions and overcrowding (UN-HABITAT 2007b). Inadequate access to clean water and sanitation, in particular, are a direct cause of a substantial proportion of deaths of infants annually (UNDP 2006). Poor water quality and quantity and inadequate sanitation are linked to a number of waterborne and water-washed diseases (UNDP 2006).

Greater morbidity and mortality among urban slum children is not simply the consequence of household level deficiencies (e.g., infrastructural problems, lack of access to basic needs) but also includes health issues arising within the context of the broader slum settlement (Awasthi and Agarwal 2003; Bartlett 2003; Agarwal and Taneja 2005). Inadequate water drainage and waste removal often creates areas of contamination extending throughout the surrounding community (Bartlett 2003); many slums lack safe places for children to play outdoors (Satterthwaite 1993; Bartlett 2003), and indoor and outdoor chemical pollutants that compromise the health of children are frequently encountered in low-income urban areas (Satterthwaite 1993). Although they often border and even roughly encircle urban areas, moreover, in general slums are socially, politically, and economically isolated from the broader urban setting and their residents lack access to many formal institutions in society.

Micro and meso-level medical science research indeed illustrates that infants and young children residing in urban slums are subject to a litany of diseases. Neonatal mortality, or death within the first 28 days, is commonplace in many urban slums and is generally preceded by sepsis, perinatal asphyxia, and prematurity (Fernandez, Mondkar, and Mathai 2003; Vaid et al. 
2007). Beyond the neonatal period infants residing in urban slums frequently die of diarrheal disease and respiratory infections (Vaid et al. 2007); high rates of diarrheal disease, in particular, is a stark reflection of the lack of clean drinking water and adequate sanitation facilities (Fotso et al. 2007; Vaid et al. 2007).

Home births not accompanied by a trained medical professional are also commonplace in many urban slums (Hoque and Selwyn 1996; Gulati and Jaswal 1998; Fernandez et al. 2003; Rahi et al. 2006); this contributes to late recognition of neonatal illness, inadequate antenatal care, and delays in seeking appropriate medical services (Fernandez et al. 2003). Further, many slum children are malnourished, increasing their susceptibility to illness (Bartlett 2003; Ghosh and Shah 2004; Wagstaff et al. 2004). Research illustrates children living in urban slums in India, for example, are more malnourished than non-slum urban and rural children (Ghosh and Shah 2004).

Rapid urbanization in many less developed countries since mid-century, it is important to note, is largely a response to exogenous factors rather than a natural, evolutionary transition along the path to modernity. As Davis (2006) highlights, urbanization in many LDCs is rooted in the colonial history and artificial repression of urban in-migration followed by generally rapid rates of urban growth after the cessation of colonial rule. Further, foreign direct investment patterns, external debt and associated structural adjustment programs, and consequent state retrenchment has profoundly reshaped the rural-urban character of developing countries. The concept of "overurbanization," embodied in a higher than expected proportion of the total population residing in urban areas relative to concurrent level of economic development, has long been a concern of scholars embracing a critical political economy perspective (Kentor 1981; Timberlake and Kentor 1983; Bradshaw 1985; 1987; Smith 1987). The size and robustness of urban economies, in turn, is often remarkably disconnected from the size of the surrounding urban population, as rapid in-migration is induced by rural poverty rather than urban formal sector employment growth (Bradshaw 1987; Davis 2006).

The expansion of urban slums is not simply rooted in rapid urbanization, however. External debt burden in concert with rapid urban in-migration is argued to underlie the expansion of urban slums in the developing countries in recent decades (UN-HABITAT 2003a; 2003b; Davis 2006). Debt promotes substantial capital outflow and constrains productive investment in the domestic economy (Ferraro and Rosser 1994; UN-HABITAT 2003b; 2005). Debt service payments are a drain on state income that could alternatively be invested in the upgrading of urban public services, including housing and improved water and sanitation provisioning (UNHABITAT 2003b). The external debt burden, in turn, constrains state planning efforts as well as inhibits the capacity of the state to mollify the deleterious effects of transnational corporate influence on the poorest segments of the population (Bradshaw and Huang 1991; Bradshaw and Wahl 1991); it also contributes to currency devaluation and a reduction in consumer purchasing power--all within a context of rapid urbanization. Managing urban growth in a manner that capitalizes on the advantages of urbanization, while minimizing the liabilities, is increasingly difficult within a context of external debt repayment and stringent structural adjustment requirements; such challenges ostensibly find expression in an urban penalty that impacts the health of children. 


\section{JOURNAL OF WORLD-SYSTEMS RESEARCH}

\section{MODEL ESTIMATION TECHNIQUES}

For the first analysis we estimate a first-difference model. In a first difference model, change in the dependent variable over time is regressed on change in the independent variables. To allow for more meaningful comparisons across nations, we calculate a "relative change" model, which, in essence, assumes that the percentage change in the dependent variable is a linear function of the percentage change in the independent variable, all else being equal. Technically, relative change models are "difference of logs models," which means that the point estimates of the two time periods for the outcome and all predictors are first logged and then differenced. The firstdifference model has many advantages. First, it requires only two point estimates that are reasonably distanced, allowing for change on both sides of the equation to be modeled accordingly. Considering that data are available for only two time points 15 years apart (i.e., 1990 and 2005) for our independent variable of interest (see variable description below), such an estimation technique is quite appropriate for this study. First-difference models tend to yield more robust results because potential outliers exert less influence; it avoids out of bounds estimates, and its coefficients have a ready interpretation as the effect of one rate on the other. Further, such an estimation strategy eliminates the impact of any time-invariant predictors since their difference scores are, by construction, zero, and first-difference models for two time points yield results identical to fixed effects model estimates. A first-difference model with timevarying predictors is as follows:

$$
\left(y_{i t}-y_{i t-1}\right)=\left(\mu_{t}-\mu_{t-1}\right)+\beta\left(x_{i t}-x_{i t-1}\right)+\left(\varepsilon_{i t}-\varepsilon_{i t-1}\right)
$$

Equation 1

Subscript $i$ represents each unit of analysis (i.e., country), subscript $t$ represents the time period, $y_{i t}$ is the dependent variable for each country at each time period, $\mu_{t}$ is an intercept that may be different for each time period, and $\beta$ represents a vector of coefficients. Predictor variables that vary over time are represented by the vector $x_{i t}$, and $\varepsilon_{i t}$ represents purely random variation at each time point.

Adequate data are unavailable for two important control variables (health expenditures per capita and secondary education) for the year 1990, which precludes estimating firstdifference models with their inclusion. Thus, in a sensitivity analysis reported in Table 2 we include these two controls and estimate a simple ordinary least-squares cross-sectional regression model for child mortality for the year 2005. Such models only allow for assessing static statistical associations between levels of outcomes and predictors, but given the potential importance of these two control variables we consider these sensitivity analyses to be crucial for accurately assessing the effect of urban slum growth on child mortality in less developed countries.

\section{THE DATASET}

We analyze a cross-national dataset consisting of countries for which data are available for the dependent variable and all independent variables included in the analyses. These countries would all be considered less developed, meaning that they all fall below the upper quartile of the World Bank's (2007) income classification of nations. The key independent variable is only available for less developed countries, thereby restricting the analyses to such cases. In particular, the dataset consists of 80 countries, which we list in Table 1. Given the limited sample size and 
degrees of freedom, we limit the number of predictors in each reported model to no more than six. Due to missing data for two control variables (health expenditures per capita and secondary education), the dataset is reduced to 64 less developed countries for the cross-sectional analysis.

Table 1. Countries Included in the Study

\begin{tabular}{|lll|}
\hline Algeria & Ghana & Niger \\
Angola* & Guatemala & Nigeria \\
Argentina & Guinea & Pakistan \\
Belize & Guinea-Bissau* & Panama \\
Benin & Guyana & Paraguay \\
Bhutan & Honduras & Peru \\
Bolivia* & India & Philippines \\
Botswana & Indonesia & Rwanda \\
Brazil & Iran & Senegal \\
Burkina Faso & Jamaica & Sierra Leone* \\
Burundi & Jordan & South Africa \\
Cameroon* & Kenya & Sri Lanka* \\
Chad & Laos & Suriname \\
Chile & Lebanon & Syrian Arab Rep. \\
China* & Lesotho & Tanzania* \\
Colombia & Madagascar & Thailand \\
Congo* & Malawi & Togo \\
Congo, Dem. Rep.* & Mali & Tunisia \\
Costa Rica & Mauritania & Turkey \\
Dominican Republic & Mexico & Uganda \\
Ecuador & Mongolia & Uruguay \\
Egypt* & Morocco & Viet Nam* \\
El Salvador & Mozambique & Yemen \\
Ethiopia & Namibia & Zambia \\
Gabon* & Nepal & Zimbabwe* \\
Gambia* & Nicaragua & \\
\hline \multicolumn{1}{c}{ Note: ${ }^{*}$ denotes countries excluded from the cross-sectional model } \\
& & \\
\hline
\end{tabular}

\section{Dependent Variable}

The dependent variable is child mortality rate, which we obtain from the World Resources Institute's online Earthtrends database (http://earthtrends.wri.org), who obtain them from the United Nations Children's Fund (UNICEF) online childinfo.org database. This measure refers to the probability of a child dying between birth and the age of five, expressed per 1,000 live births.

\section{Key Independent Variable}




\section{JOURNAL OF WORLD-SYSTEMS RESEARCH}

Percent of the total population living in urban slum conditions is a relatively new measurement available from the UN-HABITAT UrbanInfo database (http://www.devinfo.info/urbaninfo/). Since they are newly available and thus not employed in prior comparative research, these data require a relatively more detailed description. All other measures used in the current study are common in prior research. For these estimates, an urban household is defined as a slum dwelling if it lacks one or more of the following: access to an improved water supply, access to improved sanitation, sufficient living area, and durability of construction. More specifically, an improved water supply is one that provides a sufficient quantity of water for family use (at least 20 liters/person/day), at an affordable price (less than $10 \%$ of total household income), without requiring extreme effort to obtain (less than one hour a day for the minimum sufficient quantity). In addition, an improved water supply consists of the following delivery systems: piped connection to house or plot, public stand pipe serving no more than 5 households, bore hole, protected dug well, protected spring, or rain water collection. Improved sanitation consists of a private or public toilet shared between a reasonable number of people. Improved sanitation consists of the following services: direct connection to public sewer, direct connection to a septic tank, pour flush latrine, or a ventilated pit latrine. A living area is considered sufficient if there are no more than 3 people per habitable room (minimum of 4 square meters of space). A dwelling is defined as durable if it is built in a non-hazardous location and exhibits structural qualities adequate to protect its inhabitants from the extremes of climatic conditions, including rain, heat, cold, and humidity. Point estimates for the data are only available for less developed countries for 1990 and 2005, which restricts the national representation and temporality of the current study.

\section{Additional Independent Variables in the First-Difference Model}

Gross domestic product (GDP) per capita is included as a control for level of economic development. These data, which we gather from the World Bank (2007), are measured in 2000 U.S. dollars. Prior research consistently shows a negative association between child mortality rates and level of economic development in less developed countries (e.g. Shen and Williamson 2001).

We control for fertility rate, which is known to be a key contributor to child mortality (e.g., Heuveline 2001; Brady, Kaya, and Beckfield 2007; Jorgenson 2009; Rice 2008). Generally speaking, as fertility rates increase, so do child mortality rates, since more fertility means more chances for mortality, all else being equal. The measures of fertility rates, which we obtain from the World Bank (2007), represent the number of children that would be born to a woman if she were to live to the end of her childbearing years and bear children in accordance with current age-specific fertility rates.

Exports as percent total GDP is included to control for a country's level of integration in the world economy. These data are obtained from the World Bank (2007). Neoliberal perspectives (e.g., Gilpin 2001) would posit that greater world economy integration of this form will stimulate economic development and thus increase human well being, which would involve lowering child mortality rates. Conversely, critical globalization perspectives (e.g., Appelbaum and Robinson 2005) would posit that higher levels of exports as percent GDP for less developed countries is a structural mechanism that partially allows for more developed countries to 
maintain favorable terms of trade, thereby suppressing domestic economic development and well being within the former, which could lead to increases in child mortality rates.

\section{Additional Independent Variables in the Cross-Sectional Model}

Health expenditures per capita is included in the cross-sectional analyses. This measure as well as the next (secondary education) is currently unavailable for an adequate number of countries for the year 1990, and their availability for 2005 is limited, especially for health expenditures per capita. Thus, the sample size is reduced to 64 countries in the cross-sectional analyses reported in Table 3. As would be expected, prior research links health expenditures to lower mortality rates (e.g. Shandra et al. 2004). These data, which we obtain from the World Bank (2007), measure the average amount of total health expenditures per person in U.S. dollars. Health expenditures are the sum of public and private health expenditures, and include the provision of health services (preventive and curative), family planning activities, nutrition activities and emergency aid designated for health.

Secondary education is included as a measure of human capital in the cross-sectional analyses. More specifically, these data, which we gather from the World Bank (2007), quantify percent gross secondary school enrollment. Gross enrollment ratio is the ratio of total enrollment, regardless of age, to the population of the age group that officially corresponds to the level of education shown. According to the World Bank (2007), secondary education completes the provision of basic education that began at the primary level, and aims at laying the foundations for lifelong learning and human development, by offering more subject- or skill-oriented instruction using more specialized teachers. Prior research links this form of human capital to lower levels of child mortality rates (e.g., Frey and Field 2000; Shen and Williamson 2001).

\section{FINDINGS}

The first-difference model and the cross-sectional model estimates are reported in Table 2. The first difference model includes percent total population living in urban slum conditions, GDP per capita, fertility rate, and exports as percent total GDP. The cross-sectional model includes health expenditures per capita and secondary education as additional statistical controls as well as percent total population living in urban slum conditions, GDP per capita, and fertility rate. For each predictor we provide unstandardized coefficients (flagged for statistical significance), standard errors, standardized coefficients, and variance inflation factor scores (VIFs). VIFs are a common measure used to detect multicollinearity in linear regression, which can potentially lead to spurious results. We also report the adjusted r-square for each model. 
111 JOURNAL OF WORLD-SYSTEMS RESEARCH

Table 2. Unstandardized Coefficients for the Regression of Child Mortality Rates on Selected Independent Variables: First-Difference (1990-2005) and Cross-sectional (2005) Model Estimates

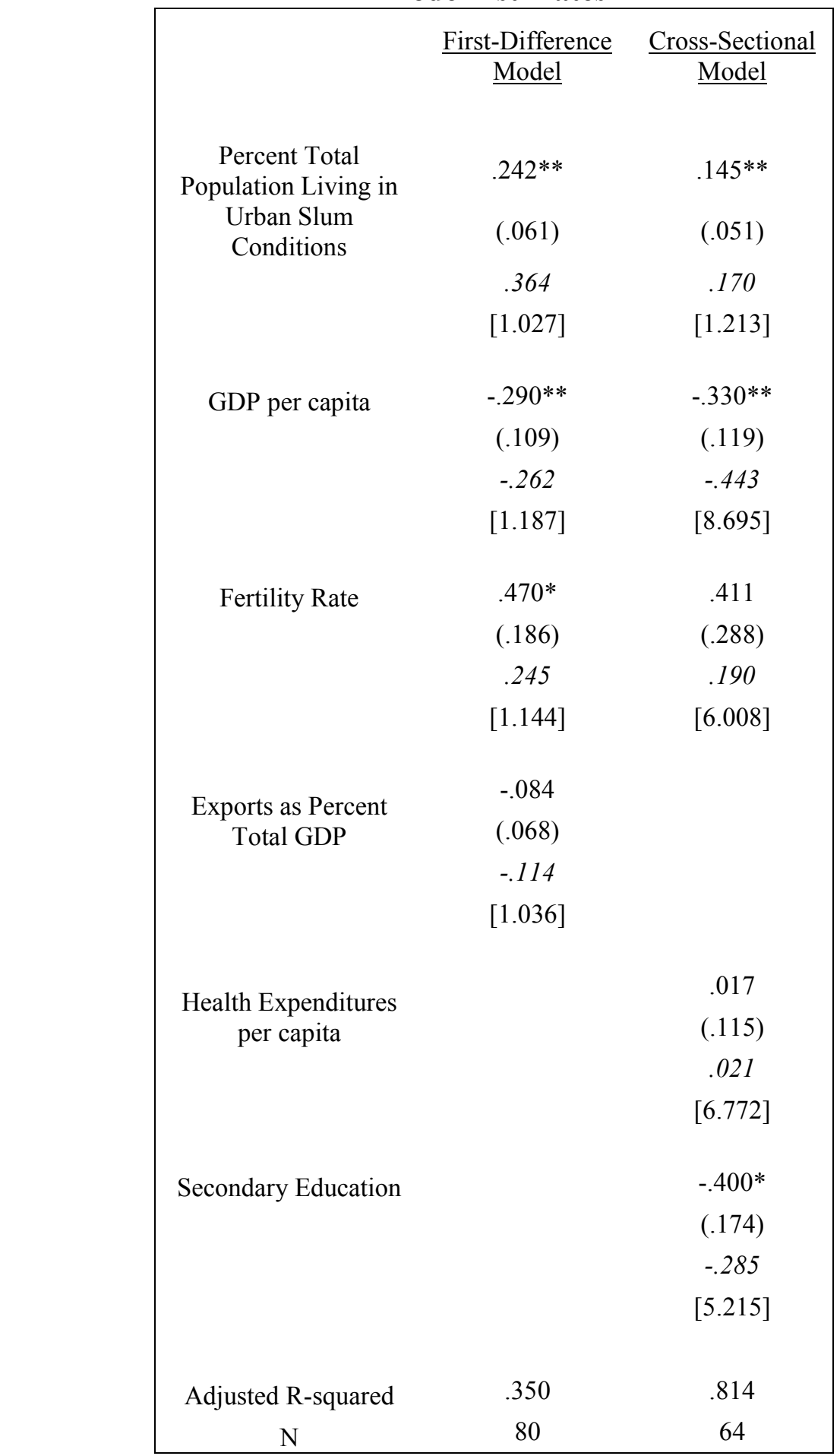

Notes: unstandardized coefficients flagged for statistical significance; ${ }^{*} \mathrm{p}<.05 * * \mathrm{p}<.01$ (two-tailed); standard errors in parentheses; standardized coefficients in italics; variance inflation factor scores in brackets 
As expected, the effect of GDP per capita on child mortality rates is negative and statistically significant. Contrarily, yet as expected, the effect of fertility rate is positive and statistically significant. These results are very consistent with prior research and illustrate the importance in controlling for both when studying the determinants of child mortality in less developed countries. The effect of exports as a percent total GDP is non-significant, which provides little support for neoclassical arguments or critical globalization propositions concerning the well being impacts of world-economic integration. However, such research questions and theoretical contestations are not the focus of this study. We note that in sensitivity analyses available upon request, we also control for urban population as percent total population. As a change score, this form of urbanization is weakly correlated with our urban slums change measure at only .19 for the sample of nations in the reported analyses. Thus, these two measures capture very different characteristics of the urban populations of less developed nations. In the sensitivity regression analyses the effect of urban population on child mortality is non-significant and close to null, while the positive effect of urban slum growth remains statistically significant.

Turning to the results of interest, the effect of percent total population living in urban slum conditions is positive, statistically significant, and moderately strong in magnitude. More specifically, cetiris paribus, from 1990 to 2005 a one percent increase in the percent total population living in urban slum conditions leads to a .242 percent increase in child mortality rates for the sample of less developed countries. Variance inflation factor scores are all well within acceptable limits, indicating the estimated first-difference model is not biased due to multicollinearity.

The results of the cross-sectional analysis indicate that child mortality rate is positively associated with percent of the total population living in urban slum conditions in 2005, and the association is statistically significant. Similar to the first-difference model estimates, the effect of GDP per capita is negative. However, the association between child mortality rate and fertility rate is non-significant. The effect of health expenditures per capita on child mortality rates is non-significant while the effect of secondary education is negative and significant. We speculate that the null findings (i.e., fertility rate and health expenditures per capita) are attributed to high multicollinearity. The variance inflation factor (VIF) score for health expenditures per capita is 6.772 while the VIFs for fertility rate (6.008), GDP per capita (8.695), and secondary education (5.215) are relatively high as well. The inflated VIFs are not surprising since all four point estimates are highly correlated with one another for the analyzed dataset. However, these characteristics do not influence the stability of the positive effect of percent total population living in urban slum conditions on child mortality rates in 2005. Elsewhere we also control for exports as percent GDP in 2005, and its effect is non-significant while its inclusion does not suppress the positive effect of percent of the total population living in urban slum conditions.

\section{CONCLUSION}

The growth of urban slums in the LDCs is a structural trend producing concentrated disadvantage (Vlahov et al. 2007) recognizable in the overcrowding and substandard living conditions enveloping nearly one billion people worldwide. Further, their historically unprecedented rise threatens to undercut the presumed public health advantages of urban life in ways many researchers have yet to fully consider.

The intent of the present study is to empirically examine the potential social production of child mortality by focusing on the direct influence of urban slum prevalence or proportion of 


\section{JOURNAL OF WORLD-SYSTEMS RESEARCH}

the total population living in urban slum conditions among the 80 developing countries with available data. This analytical focus is grounded in the meta-theoretical assumption derived from social epidemiology suggesting the built environment is not simply a container for socialorganizational dynamics but has independent effects on physiological processes and is thus central to prevailing patterns of health and illness. Disparities in health and illness often follow from contextual social determinants shaping variance in risk encountered by differing segments of a population. Such patterns, in turn, constitute "biological reflections of social fault lines" whereby disease distribution is forged through relative power, privilege, and inequality (Krieger and Zierler 1996; Farmer 1999; Krieger 2001).

Findings for the first-difference panel regression analysis of less developed countries illustrate that urban slum growth, measured as the percent of the population residing in urban slum conditions, does indeed contribute to child mortality rates from 1990-2005, net of economic development, fertility rates, and other factors. The cross-sectional analysis of child mortality in 2005 that includes additional controls provide further evidence of the urban slum / mortality relationship. Overall, the results of the present study illustrate that urban slum prevalence exhibits a substantial impact on child mortality across a large number of less developed countries. Urban slum prevalence constitutes a dimension of the social production of mortality rooted in prevailing social inequities and economic organization that underlies the formation of urban slum settlements. Thus, child mortality is not simply reducible to individual-level biological and behavioral risk factors. Urban slums are a crucial context wherein susceptibility to disease and illness promote the disproportionate death of children in less developed countries.

\section{REFERENCES}

Agarwal, S. and S. Taneja. 2005. "All Slums are not Equal: Child Health Conditions Among the Urban Poor." Indian Pediatrics 42: 233-244.

Appelbaum, R. and W. Robinson. 2005. Critical Globalization Studies. New York: Routledge.

Awasthi, S. and S. Agarwal. 2003. "Determinants of Childhood Mortality and Morbidity in Urban Slums in India." Indian Pediatrics 40: 1145-1161.

Bartlett, S. 2003. "Water, Sanitation, and Urban Children: The Need to go Beyond 'Improved' Provision." Environment and Urbanization 15(2): 57-70.

Berkman, L. and I. Kawachi. 2000. “A Historical Framework for Social Epidemiology.” Pp. 3-12 in Social Epidemiology, edited by L. Berken and I. Kawachi. New York: Oxford University Press.

Bradshaw, York W. 1985. "Overurbanization and Underdevelopment in Sub-Saharan Africa: A Cross-National Study." Studies in Comparative International Development 20(3): 74101.

------. 1987. "Urbanization and Underdevelopment: A Global Study of Modernization, Urban Bias, and Economic Dependency." American Sociological Review 52: 224-239. 
Bradshaw, York W. and Ana-Maria Wahl. 1991. "Foreign Debt Expansion, the International Monetary Fund, and Regional Variation in Third World Poverty." International Studies Quarterly 35: 251-272.

Bradshaw, York W. and Jie Huang. 1991. "Intensifying Global Dependency: Foreign Debt, Structural Adjustment, and Third World Underdevelopment." The Sociological Quarterly 32(3): 321-342.

Brady, D., Y. Kaya, and J. Beckfield. 2007. "Reassessing the Effect of Economic Growth on Well-Being in Less-Developed Countries, 1980-2003." Studies in Comparative International Development 42: 1-35.

Davis, Mike. 2006. Planet of Slums. New York: Verso.

Dunlap, R., W. Michelson, and G. Stalker. 2001. "Environmental Sociology: An Introduction." Pp. 1-32 in Handbook of Environmental Sociology, edited by R. Dunlap and W. Michelson. Westport, CT: Greenwood Press.

Engels, F. 1968 [1845]. The Condition of the Working Class in England. Palo Alto, CA: Stanford University Press.

Farmer, Paul. 1999. Infections and Inequalities: The Modern Plagues. Berkeley: University of California Press.

Farmer, Paul, Bruce Nizeye, Sara Stulac, and Salmaan Keshavjee. 2006. "Structural Violence and Clinical Medicine." PLoS Medicine 3(10): 1686-1691.

Fernandez, Armida, Jayshree Mondkar, and Sheila Mathai. 2003. "Urban Slum-Specific Issues in Neonatal Survival." Indian Pediatrics 40: 1161-1166.

Ferraro, Vincent and Melissa Rosser. 1994. "Global Debt and Third World Development." Pp. 332-355 in World Security: Challenges for a New Century, edited by Michael Klare and Daniel Thomas. New York: St. Martin's Press.

Fitzpatrick, Kevin and Mark LaGory. 2000. Unhealthy Places: The Ecology of Risk in the Urban Landscape. New York: Routledge.

Fotso, Jean-Christophe, Alex Chika Ezeh, Nyovani Janet Madise, and James Ciera. 2007. "Progress Towards the Child Mortality Millennium Development Goal in Urban SubSaharan Africa: The Dynamics of Population Growth, Immunization, and Access to Clean Water." BMC Public Health 7: 218.

Frey, R.S. and C. Field. 2000. "The Determinants of Infant Mortality in Less Developed Countries: A Cross-National Test of Five Theories." Social Indicators Research 52: 215234.

Galtung, Johan. 1969. "Violence, Peace, and Peace Research." Journal of Peace Research 6(3): 167-191.

Ghosh, S. and D. Shah. 2004. "Nutritional Problems in Urban Slum Children." Indian Pediatrics 41: 682-696.

Gilpin, R. 2001. Global Political Economy. Princeton, NJ: Princeton University Press.

Gulati, JK and S. Jaswal. 1998. "Maternal and Child Health Care in Slums of Ludhiana City." Indian Journal of Maternal and Child Health 9(1): 48-51.

Heuveline, P. 2001. "Demographic Pressure, Economic Development, and Social Engineering: An Assessment of Fertility Declines in the Second Half of the Twentieth Century." Population Research Policy Review 20: 265-396.

Hoque, Ashraful and Beatrice J. Selwyn. 1996. "Birth Practice Patterns in Urban Slums of Dhaka, Bangladesh.” Women \& Health 24(1): 41-58. 


\section{JOURNAL OF WORLD-SYSTEMS RESEARCH}

Jorgenson, A.K. 2009. "Political-Economic Integration, Industrial Pollution, and Human Health: A Panel Study of Less-Developed Countries, 1980-2000.” International Sociology 24: 115-143.

Kentor, Jeffrey. 1981. "Structural Determinants of Peripheral Urbanization: The Effects of International Dependence." American Sociological Review 46: 201-211.

Kilmartin, Leslie. 2001. "Designing the Built Environment." Pp. 167-191 in Handbook of Environmental Sociology, edited by Riley E. Dunlap and William Michelson. Westport, CT: Greenwood Press.

Krieger, N. 1999. "Embodying Inequality: A Review of Concepts, Measures, and Methods for Studying Health Consequences of Discrimination. International Journal of Health Services 29(2): 295-352.

Krieger, Nancy. 2001. "Theories for Social Epidemiology in the $21^{\text {st }}$ Century: An Ecosocial Perspective." International Journal of Epidemiology 30(4): 668-677.

Krieger, Nancy and Sally Zierler. 1996. "What Explains the Public's Health-A Call for Epidemiologic Theory." Epidemiology 7(1): 107-109.

Link, B., \& Phelan, J. 1996. "Understanding Sociodemographic Differences in Health-The Role of Fundamental Social Causes." American Journal of Public Health 86(4): 471-473.

Rahi, Manju, D.K. Taneja, Amrita Misra, N.B. Mathur, and Suresh Badhan. 2006. "Newborn Care Practices in an Urban Slum of Delhi." Indian Journal of Medical Sciences 60(12): 506-513.

Rice, J. 2008. "Material Consumption and Social Well-Being Within the Periphery of the World Economy: An Ecological Analysis of Maternal Mortality." Social Science Research 37: 1292-1309.

Satterthwaite, D. 1993. "The Impact on Health of Urban Environments." Environment and Urbanization 5(2): 87-111.

Sclar, E., P. Garau, and G. Carolini. 2005. "The $21^{\text {st }}$ Century Health Challenge of Slums and Cities." The Lancet 365: 901-903.

Shandra, J., J. Nobles, B. London, and J. Williamson. 2004. "Dependency, Democracy, and Infant Mortality: A Quantitative, Cross-National Analysis of Less Developed Countries." Social Science \& Medicine 59: 321-333.

Shen, C.E., and J. Williamson. 2001. "Accounting for Cross-National Differences in Infant Mortality Decline (1965-1991) Among Less Developed Countries: Effects of Women's Status, Economic Dependency, and State Strength.” Social Indicators Research 53: 257288.

Smith, David A. 1987. "Overurbanization Reconceptualized: A Political Economy of the WorldSystem Approach." Urban Affairs Quarterly 23(2): 270-294.

Timberlake, Michael and Jeffrey Kentor. 1983. "Economic Dependence, Overurbanization, and Economic Growth: A Study of Less Developed Countries." The Sociological Quarterly 24: 489-507.

Turshen, M. 1977. "The Political Ecology of Disease." Review of Radical Political Economics 9(1): 45-60.

United Nations Development Programme [UNDP]. 2006. Human Development Report. New York: Oxford University Press.

United Nations Human Settlements Programme [UN-HABITAT]. 2003a. Slums of the World: The Face of Urban Poverty in the New Millennium? London: Earthscan. 
-----. 2003b. The Challenge of Slums: Global Report on Human Settlements 2003. London: Earthscan.

-----. 2005. Financing Urban Shelter: Global Report on Human Settlements 2005. London: Earthscan.

-----. 2006. State of the world's cities report 2006/7. London: Earthscan.

-----. 2007a. The Urban Penalty: The Poor Die Young. London: Earthscan.

-----. 2007b. Slums: Some Definitions. London: Earthscan.

-----. 2008. UrbanInfo Database. Available at http://www.devinfo.info/urbaninfo/.

United Nations Population Fund [UNFPA]. 2007. State of World Population 2007.

Vaid, A., A. Mammen, B. Primrose, and G. Kang. 2007. "Infant Mortality in an Urban Slum." Indian Journal of Pediatrics 74: 449-453.

Vlahov, David, Nicholas Freudenberg, Fernando Proietti, Danielle Ompad, Andrew Quinn, Vijay Nandi, and Sandro Galea. 2007. "Urban as a Determinant of Health." Journal of Urban Health: Bulletin of the New York Academy of Medicine 84(1): i16-i26.

Wagstaff, A., F. Bustreo, J. Bryce, and M. Claeson. 2004. "Child Health: Reaching the Poor." American Journal of Public Health 94(5): 726-736.

Waitzkin, H. 1981. "The Social Origins of Illness: A Neglected History.” International Journal of Health Services 11(1): 77-103.

World Bank. 2007. World Development Indicators (CD ROM version). Washington, DC: World Bank.

World Resources Institute. 2009. Earthtrends Database.

Yankauer, Alfred, Jr. 1950. "The Relationship of Fetal and Infant Mortality to Residential Segregation: An Inquiry into Social Epidemiology.” American Sociological Review 15: 644-648. 